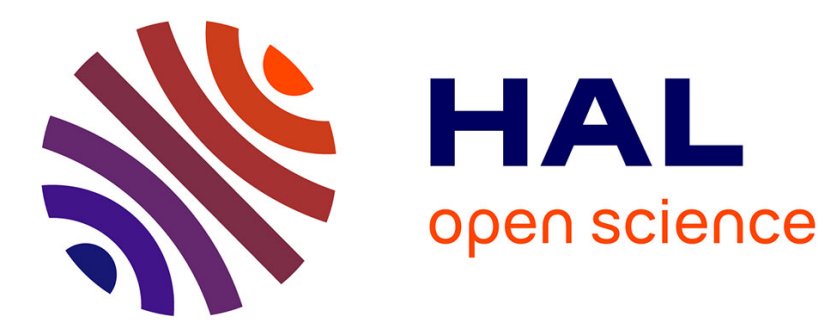

\title{
Upper tropospheric humidity and cirrus geometrical and optical thickness: Relationships inferred from 1 year of collocated AIRS and CALIPSO data
}

\author{
Nicolas Lamquin, Claudia J. Stubenrauch, Jacques Pelon
}

\section{- To cite this version:}

Nicolas Lamquin, Claudia J. Stubenrauch, Jacques Pelon. Upper tropospheric humidity and cirrus geometrical and optical thickness: Relationships inferred from 1 year of collocated AIRS and CALIPSO data. Journal of Geophysical Research: Atmospheres, 2008, 113 (D8), pp.D00A08. 10.1029/2008JD010012 . hal-00325291

\section{HAL Id: hal-00325291 \\ https://hal.science/hal-00325291}

Submitted on 7 Mar 2016

HAL is a multi-disciplinary open access archive for the deposit and dissemination of scientific research documents, whether they are published or not. The documents may come from teaching and research institutions in France or abroad, or from public or private research centers.
L'archive ouverte pluridisciplinaire $\mathbf{H A L}$, est destinée au dépôt et à la diffusion de documents scientifiques de niveau recherche, publiés ou non, émanant des établissements d'enseignement et de recherche français ou étrangers, des laboratoires publics ou privés. 


\title{
Upper tropospheric humidity and cirrus geometrical and optical thickness: Relationships inferred from 1 year of collocated AIRS and CALIPSO data
}

\author{
N. Lamquin, ${ }^{1}$ C. J. Stubenrauch, ${ }^{1}$ and J. Pelon ${ }^{2}$ \\ Received 22 February 2008; revised 25 June 2008; accepted 15 July 2008; published 25 September 2008.
}

[1] Profiles of relative humidity with respect to ice (RHice) determined from spaceborne passive remote sensing suffer a lack of vertical and spatial resolutions. RHice distributions show dry biases compared to in situ observations because geometrically thin moist layers are integrated within coarser vertical resolutions, a direct effect being the underestimation of ice supersaturation (RHice $>100 \%$ ) occurrence. Collocated data from the Atmospheric Infrared Sounder (AIRS) and the Cloud-Aerosol Lidar and Infrared Pathfinder Satellite Observation (CALIPSO) provide the opportunity to investigate relationships between RHice and geometrical thickness and optical depth of high clouds near the tropopause. "Apparent" optical depths are derived for single-layer high clouds from CALIPSO. By comparing these "apparent" optical depths to cloud infrared emissivities derived from AIRS the multiple scattering contribution is estimated and the optical depths are corrected. Mean RHice increases with cloud geometrical thickness but remains low compared to $100 \%$ except for very vertically extended clouds. Optically thicker clouds show on average larger geometrical thickness and larger relative humidity than optically thinner clouds. However, for a comparable geometrical thickness, optically thinner clouds are on average slightly more humid. This study concludes that cloud geometrical thickness has a greater influence than cloud optical depth on RHice integrated within a coarse vertical resolution. Limitations of AIRS humidity observations regarding the detection of ice supersaturation are discussed.

Citation: Lamquin, N., C. J. Stubenrauch, and J. Pelon (2008), Upper tropospheric humidity and cirrus geometrical and optical thickness: Relationships inferred from 1 year of collocated AIRS and CALIPSO data, J. Geophys. Res., 113, D00A08, doi:10.1029/2008JD010012.

\section{Introduction}

[2] Relative humidity with respect to ice (RHice) in the upper troposphere has been given special attention only recently, and its importance in climate has raised increasing concerns [e.g., Gierens and Spichtinger, 2000; Gettelman et $a l ., 2006]$. Ice clouds (cirrus) need a large degree of ice supersaturation (RHice $>100 \%$ ) to form, depending on thermodynamical and chemical conditions [e.g., Haag et al., 2003]. Homogeneous freezing, which implies larger RHice values is usually used in climate models. However, climate feedback from ice clouds is presently poorly known, and the contribution of heterogeneous versus homogeneous freezing processes is still under discussion [Lohmann et al., 2004]. Despite the need of high ice supersaturation, in situ measurements [e.g., Ovarlez et al., 2002; Spichtinger et al., 2004; Immler et al., 2007] have shown that distributions of

\footnotetext{
${ }^{1}$ Laboratoire de Météorologie Dynamique, Ecole Polytechnique, IPSL, CNRS, Palaiseau, France.

${ }^{2}$ Service d'Aéronomie, IPSL, Université Pierre et Marie Curie, CNRS, Paris, France.

Copyright 2008 by the American Geophysical Union. 0148-0227/08/2008JD010012
}

RHice inside cirrus clouds are peaked at a value of RHice $\approx$ $100 \%$. This infers that, as soon as ice clouds are formed, ice supersaturation is no longer the dominant feature. Recent studies [Kley et al., 2007; Luo et al., 2007] using 10 years of in situ data show RHice peaking around $110 \%$ near convective areas over the tropical central Atlantic.

[3] RHice profiles and cirrus properties determined from spaceborne passive remote sensing suffer, in general, a lack of vertical and spatial resolutions. RHice distributions are usually obtained for pressure layers larger than the typical vertical thickness of the clouds [e.g., Stubenrauch and Schumann, 2005; Kahn et al., 2008] and peak around lower values compared to in situ RHice distributions inside cirrus.

[4] Since global insights of the relationships between upper tropospheric humidity (UTH) and cirrus properties can only be obtained by using satellite data, it is important to determine how to consider ice supersaturation occurring within atmospheric layers. An analysis of the behavior of RHice with vertical extent and optical depth of the embedded cirrus will support that ice supersaturation can occur even when RHice retrieved with a coarse vertical resolution is lower than $100 \%$.

[5] In this article we investigate relationships between RHice and cirrus vertical thickness and optical depth in 
pressure layers near the tropopause, for tropics and for midlatitudes. We use 1 year of collocated data from satellite observations of the Atmospheric Infrared Sounder (AIRS) and the Cloud-Aerosol Lidar with Orthogonal Polarization (CALIOP), both instruments of the A-Train satellite constellation. Cloud-Aerosol Lidar and Infrared Pathfinder Satellite Observation (CALIPSO) level 2 (L2) data [Winker et al., 2007] provide so far number of cloud layers and their vertical extension. AIRS L2 data provide atmospheric temperature and humidity profiles [Susskind et al., 2003]. Both data sets are described in section 2 as well as an estimation of CALIPSO cirrus "apparent" optical depths using level 1 (L1) profiles of backscattered radiation at $532 \mathrm{~nm}$. One difficulty is to estimate the contribution of multiple scattering to these "apparent" optical depths. The collocation of AIRS and CALIPSO cloud properties, described in section 3 permits to derive the correction factor linked to multiple scattering by comparing the "apparent" cloud optical depth from CALIPSO to cloud infrared emissivity derived from AIRS [Stubenrauch et al., 2008] for single-layer high cloud scenes. In section 4 we finally present the analysis relating RHice to cirrus geometrical thickness and optical depth, and section 5 presents the conclusions of this article.

\section{Data}

[6] The "A-Train" is a satellite constellation [Stephens et al., 2002] conceived to improve our understanding of Earth's climate in an unprecedented way. It involves a leading satellite (Aqua) and four other satellites following it on the very same Sun-synchronous polar orbit. Each instrument provides a specific view of the atmosphere and completes the description given by the other instruments. Among the large set of instruments, we use AIRS on board Aqua and CALIOP on board CALIPSO.

\subsection{CALIPSO Mission and Cloud Products}

[7] CALIPSO is the product of a collaboration between France's Centre National d'Etudes Spatiales (CNES) and National Aeronautics and Space Administration (NASA) [Winker et al., 2003]. It is the first spaceborne lidar for a long-duration mission. A previous spaceborne lidar experiment by NASA, the Lidar In-space Technology Experiment (LITE), has proven successful [Winker et al., 1996] and opened the way to long-term missions. A lidar uses a linearly polarized laser beam, and the depolarization of the received return signal is used to determine and discriminate the vertical distribution of water clouds, ice clouds and aerosol masses [e.g., Sassen, 1991; Winker et al., 2007]. Compared to ground-based and airborne lidars the signal-tonoise ratio is worse for CALIOP as the satellite is much farther from the observed scene [McGill et al., 2007]. Particularly, the signal noise is increased during the day, and it is more reliable to use nighttime data. Performance of CALIOP is summarized in [Winker et al., 2007]. The instrument provides an accurate vertical profile of backscattered radiation at $532 \mathrm{~nm}$ and $1064 \mathrm{~nm}$ at a vertical resolution of $60 \mathrm{~m}$ for altitudes between 8.2 and $20.2 \mathrm{~km}$, where high clouds are situated. CALIOP is a nadir viewing instrument, and the width of each shot is $90 \mathrm{~m}$ with a $333 \mathrm{~m}$ sampling along the track. The $5 \mathrm{~km} \mathrm{L2}$ cloud products provide so far number of cloud layers and their vertical extent (top and base altitudes) averaged over $5 \mathrm{~km}$.

[8] We use version 1 of CALIPSO data, not containing optical depth products. Geometrical height is transformed to pressure using meteorological atmospheric profiles provided by the Global Modeling and Assimilation Office (GMAO). These atmospheric profiles are available in the CALIPSO L1 data. We determine cloud pressure as the pressure of the "apparent middle" of the cloud: $p_{c l d}=\left(p_{\text {base }}+p_{\text {top }}\right) / 2$. The laser device is so sensitive it detects very thin clouds (such as subvisible cirrus with optical depths lower than $\tau=0.03$ ) which are not detected using passive remote sensing [e.g., Stubenrauch et al., 2005; Wylie et al., 2007], with the exception of limb viewing instruments [e.g., Read et al., 1995; Wang et al., 1997] because of their very large path lengths. On the other hand, opaque clouds do not let the laser beam pass through. This infers an upper limit for the optical depth of 5 [Winker et al., 2003], and a clear discrimination of several cloud layers is only possible when the signal is not totally attenuated, a situation for which a surface echo is detected.

\subsection{Determination of Cirrus "Apparent" Optical Depth From CALIPSO}

[9] Since cloud optical depths are not available in the version 1 of CALIPSO L 2 cloud products and are only betaquality data in the version 2 products, we estimate the CALIPSO uppermost cloud optical depth $\left(\tau_{L I D}\right)$ by analyzing backscattered radiation at $532 \mathrm{~nm}$ from the L1 products combined with L2 cloud products. The method employed is based on the one used by Chen et al. [2002]. It uses the difference between the signal below the highest cloud and the molecular signal at the same altitude. The molecular signal can be obtained from clear sky scenes using the attenuation of the laser beam by surrounding gases. First, the molecular backscatter profile is computed using the 15 L1 backscatter profiles averaged over $5 \mathrm{~km}$, associated with L2 clear sky scenes (no cloud layer detected). To reduce the noise, averages are made over available molecular backscatter profiles within regions of $15^{\circ}$ latitude $\times 15^{\circ}$ longitude over a period of 5 days, separately for land and ocean. Then the cloud optical depth of the highest cloud layer is computed from the ratio provided by the signal just below the cloud and the molecular signal at the same height as $\tau_{L I D}=\frac{1}{2} \ln \left(\frac{S_{\text {mol }}}{S_{\text {cld }}}\right)$. Both signals are averaged over 20 points along the vertical profiles, corresponding to a vertical interval of about $1 \mathrm{~km}$. The factor $1 / 2$ comes from the fact that the beam traverses the cloud two times, the molecular signal $S_{m o l}$ is less attenuated than the signal under the cloud $S_{c l d}$, so that $\tau_{\text {LID }}$ should always be positive. This method is only used to retrieve the optical depth of the highest cloud. For the clouds underneath the highest cloud the optical depth would be overestimated because extinction by clouds underneath is acting on the signal reduced by the clouds above. Some limitations make the use of other quality flags useful as some clouds underneath are very close to the highest cloud and not many points are left to average the signal underneath this highest cloud. For the following study, we concentrate only on single-layer high clouds. Multiple scattering (MS) of light by ice crystals within clouds affects the "apparent" optical depth determined as described above. Its contribution can be estimated by 
comparing the "apparent" optical depth to the cloud visible optical depth retrieved by passive remote sensing. This will be investigated in section 3 .

\subsection{AIRS Atmospheric Profiles}

[10] On board the satellite Aqua AIRS provides atmospheric profiles of temperature and humidity [Susskind et al., 2003]. We use version 5 of AIRS L2 data. The horizontal resolution of the AIRS footprint is $13.5 \mathrm{~km}$ at nadir, and atmospheric profiles are provided at the resolution of Advanced Microwave Sounding Unit (AMSU) footprints of about $45 \mathrm{~km}$. The L2 data are coregistered in such a way, that $3 \times 3$ AIRS footprints are included in one AMSU footprint, also called a "golf ball." AIRS L2 data also provide quality flags. We only use retrieved AIRS L2 atmospheric profiles of best and good quality (from now onward simply termed "good" for both cases) in water vapor and temperature at pressure levels $p<600 \mathrm{hPa}$ [Susskind et al., 2006; Tobin et al., 2006]. This is assured by using the conditions Qual H2O $\neq 2$ and PGood > $600 \mathrm{hPa}$. If the atmosphere is too cloudy, the atmospheric profile may be of bad quality. In the L2 standard products the specific humidity $q$ is obtained as an integral over an atmospheric layer, whereas temperatures are determined at top and bottom of each layer. Therefore RHice is also determined over the atmospheric layer, as in the work by Stubenrauch and Schumann [2005]. The saturation specific humidity with respect to ice $q_{s}^{i}$ integrated over the pressure layer is obtained from the saturated partial water vapor pressure with respect to ice [Sonntag, 1990]. The latter is determined in steps of $1 \mathrm{hPa}$ from the linearly interpolated temperature profiles within the pressure layer. Relative humidity profiles are determined for six pressure layers between $100 \mathrm{hPa}$ and $500 \mathrm{hPa}$ : 100-150, 150-200, 200250, 250-300, 300-400, and 400-500 hPa. A similar method was applied to AIRS data by [Gettelman et al., 2006], and validation studies [Gettelman et al., 2004; Read et al., 2007] suggest that layers for which the water vapor content is lower than the nominal instrument sensitivity $(q=$ 20 ppmv) must be rejected.

\subsection{Determination of AIRS Cloud Properties}

[11] The AIRS cloud retrieval developed at Laboratoire de Météorologie Dynamique (LMD) [Stubenrauch et al., 2008] is based on a weighted $\chi^{2}$ method using channels around the $15 \mu \mathrm{m} \mathrm{CO}$ absorption band [Stubenrauch et al., 1999] in combination with AIRS L2 atmospheric profiles and simulated atmospheric spectral transmissivity profiles of the Thermodynamic Initial Guess Retrieval (TIGR) data set [Chédin et al., 1985; Chevallier et al., 1998]. It provides cloud pressure $p_{c l d}$, cloud temperature $T_{c l d}$ and effective infrared cloud emissivity $\epsilon_{I R}$ of the uppermost cloud layer per AIRS footprint. So far it has been applied to 1 year (September 2006 to August 2007) of AIRS data during nighttime (0130 local time (LT)) for the latitude band $30^{\circ} \mathrm{N}-$ $30^{\circ} \mathrm{S}$. Cloud height has been evaluated using CALIPSO data. For $80 \%$ of the AIRS high clouds $\left(p_{\text {cld }}<440 \mathrm{hPa}\right)$ which have been classified as single layer by CALIPSO the AIRS cloud height lies within $75 \mathrm{hPa}$ of the height of the "apparent middle" of the CALIPSO cloud [Stubenrauch et al., 2008]. These data will be used in the next section to determine the multiple scattering contribution to the CALIPSO cloud "apparent" optical depth.

\section{Synergy of AIRS and CALIPSO Cloud Properties}

[12] AIRS and CALIPSO provide data at different resolutions, CALIPSO cloud data are used at $5 \mathrm{~km}$ resolution whereas AIRS provides humidity profiles within AMSU footprints of about $45 \mathrm{~km}$ and cloud properties within AIRS footprints of about $13.5 \mathrm{~km}$. We must therefore use different collocation and selection schemes to fully exploit these resolutions.

\subsection{Collocation of CALIPSO With AIRS Relative Humidity Profiles}

[13] Humidity profiles are provided at the resolution of AIRS golf balls. One AIRS golf ball is collocated with five adjacent CALIPSO pixels, each containing a single-layer cloud. This is done in a way that the five pixels lay inside the AIRS golf ball, they are organized so that the middle pixel is the closest to the center of the golf ball. It is arguable to use more than five pixels as they only print out as a $25 \mathrm{~km}$ track inside the golf ball which is about $45 \mathrm{~km}$ wide, but using more pixels implies that they are not all inside the golf ball because the track does not necessarily cross the center of the golf ball. We then keep five pixels as a compromise with regard to the statistics. It is understood that whatever the number of CALIPSO pixels used the very narrow track $(90 \mathrm{~m})$ of pixels only represents a small portion of the golf ball. Kahn et al. [2008] have shown (their Figure 11) that no substantial difference in the relationship between RHice and geometrical cirrus cloud thickness is found whether a small or a large number of CALIPSO pixels are within the AMSU footprint. Average cloud pressure and thickness are determined with a simple algorithm taking into account the vertical extent of the cloud of each pixel given by the L 2 cloud products: average base and top pressures and altitudes are determined, from which we obtain average cloud pressure and thickness. Cases are rejected when the 5 pixels have very different cloud tops and bases (gaps between the clouds defined by each pixel).

[14] We consider the respective limitations of the instruments: nighttime data because of the lidar's best efficiency and AIRS atmospheric profiles of good quality. Therefore CALIPSO data have been collocated with AIRS atmospheric profiles over 1 year nighttime data (0130 LT) between September 2006 and August 2007 in the tropics $\left(20^{\circ} \mathrm{N}-\right.$ $20^{\circ} \mathrm{S}$ ) and in the midlatitudes $\left(40-60^{\circ} \mathrm{N}\right.$ and $\mathrm{S}$ combined).

[15] Figure 1 presents normalized distributions of cloud pressures of all single-layer high clouds $\left(p_{\text {cld }}<500 \mathrm{hPa}\right)$ according to CALIPSO as well as of single-layer high clouds with atmospheric profiles of good quality, the latter representing a total of about 35000 selected events. Especially in the tropics between 100 and $150 \mathrm{hPa}$, where most high clouds are originally detected by CALIPSO, most events are rejected either because of the humidity being lower than the instrument sensitivity $(q<20$ ppmv) or because of the tropopause lying inside the pressure layer. At altitudes lower than $150 \mathrm{hPa}$ the sensitivity selection does not infer any bias since the removed scenes represent less 

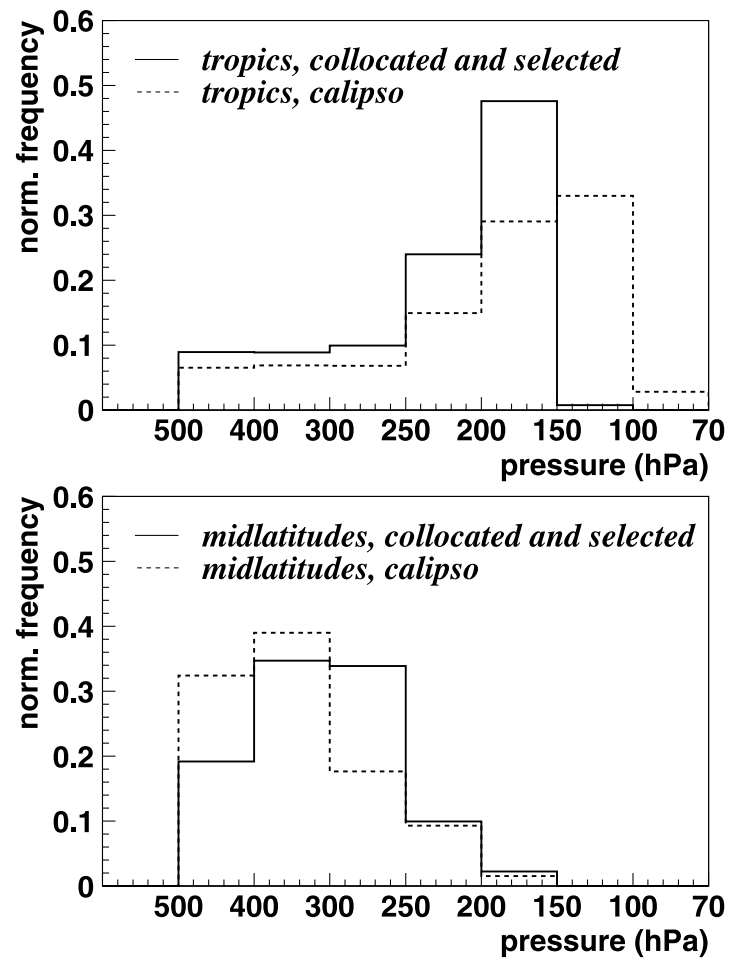

Figure 1. Normalized distributions of cloud pressure ("apparent middle" using $\left.p_{\text {cld }}=\left(p_{\text {top }}+p_{\text {base }}\right) / 2\right)$ of singlelayer high clouds seen from CALIPSO, in (top) tropics $\left(20^{\circ} \mathrm{N}-20^{\circ} \mathrm{S}\right)$ and (bottom) midlatitudes $\left(40-60^{\circ} \mathrm{N}\right.$ and $\mathrm{S}$ combined): all CALIPSO data (dashed) and data selected after collocation with AIRS.

than $1 \%$ of the number of events after the selection with regard to the tropopause.

[16] For the analysis involving RHice in section 4 layers below the tropopause (about $100 \mathrm{hPa}$ in the tropics and between 200 and $300 \mathrm{hPa}$ in the midlatitudes, depending on season and location) are selected, with temperature and humidity profiles of good quality and not including the tropopause inside the layer. Therefore, the layer $150-200 \mathrm{hPa}$ will be used for the tropics and the layer $300-400 \mathrm{hPa}$ for the midlatitudes.

[17] For comparison, we will also show results for layers $200-250 \mathrm{hPa}$ in the tropics and $250-300 \mathrm{hPa}$ in the midlatitudes (mostly summer because of the selection with regard to the tropopause). Throughout section 4 only RHice calculated with layer bottom temperature $T<240 \mathrm{~K}$ are kept to ensure that the selected cloud scenes do not mix liquid and ice phases [Pruppacher, 1994; Korolev and Isaac, 2006].

\subsection{Collocation of CALIPSO With AIRS Cloud Properties}

[18] AIRS cloud infrared emissivity $\epsilon_{I R}$ and temperature $T_{\text {cld }}$ are provided for each AIRS footprint of about $13.5 \mathrm{~km}$ in the latitude band $30^{\circ} \mathrm{N}-30^{\circ} \mathrm{S}$ between September 2006 and August 2007. We collocate each AIRS footprint identified as high cloud with the CALIPSO pixel closest to its center, containing a single-layer cloud with cloud pressure close to the one of AIRS ( $\Delta p_{\text {cld }}<50 \mathrm{hPa}$ ). The CALIPSO pixel has to lie inside the AIRS footprint. For the determi- nation of the multiple scattering correction we select a range of AIRS cloud emissivities between $\epsilon_{I R}=0.1$ and $\epsilon_{I R}=0.6$. The lower limit is chosen because of an increasing uncertainty of cloud properties toward optically thin clouds [Stubenrauch et al., 2008]. The upper limit, corresponding to a visible optical depth $\tau \approx 2$, is chosen to avoid lidar saturated profiles. Again, in order to treat only clouds containing ice crystals, we analyze only cases with $T_{\text {cld }}<$ $240 \mathrm{~K}$. This collocation scheme is used throughout section 3.3 .

\subsection{Estimation of the Multiple Scattering Contribution to CALIPSO Cirrus "Apparent" Optical Depth}

[19] Cirrus infrared emissivity $\epsilon_{I R}$ from AIRS is related to the visible optical depth $\tau_{V I S}$ by $\epsilon_{I R}=1-\exp \left(-\tau_{V I S} / \alpha\right)$. The extinction-to-absorption ratio $\alpha$, reaches 2 in the geometrical optics limit for particles large compared to the wavelength. For cirrus clouds containing small ice particles, $\alpha$ might be larger than 2 [e.g., Minnis et al., 1993; Sassen and Comstock, 2001; Platt et al., 2002].

[20] Platt [1973] has defined a correction coefficient $\eta$ as the ratio between "apparent" and visible optical depths: $\eta=$ $\tau_{L I D} / \tau_{V I S} . \eta$ varies with instrument aperture (footprint size), distance to target (cloud range) and also slightly with the microphysical properties of the clouds (essentially the shape of particles). For spaceborne lidars the multiple scattering coefficient should be smaller than 0.5 [Chepfer et al., 1999]. However, Winker [2003] suggests $\eta$ between 0.6 and 0.75 for CALIPSO using Monte Carlo simulations.

[21] In the work by Chen et al. [2002] the MS contribution is suggested to increase with the cloud optical depth and single scattering $(\eta=1)$ is proposed for $\tau$ close to 0 .

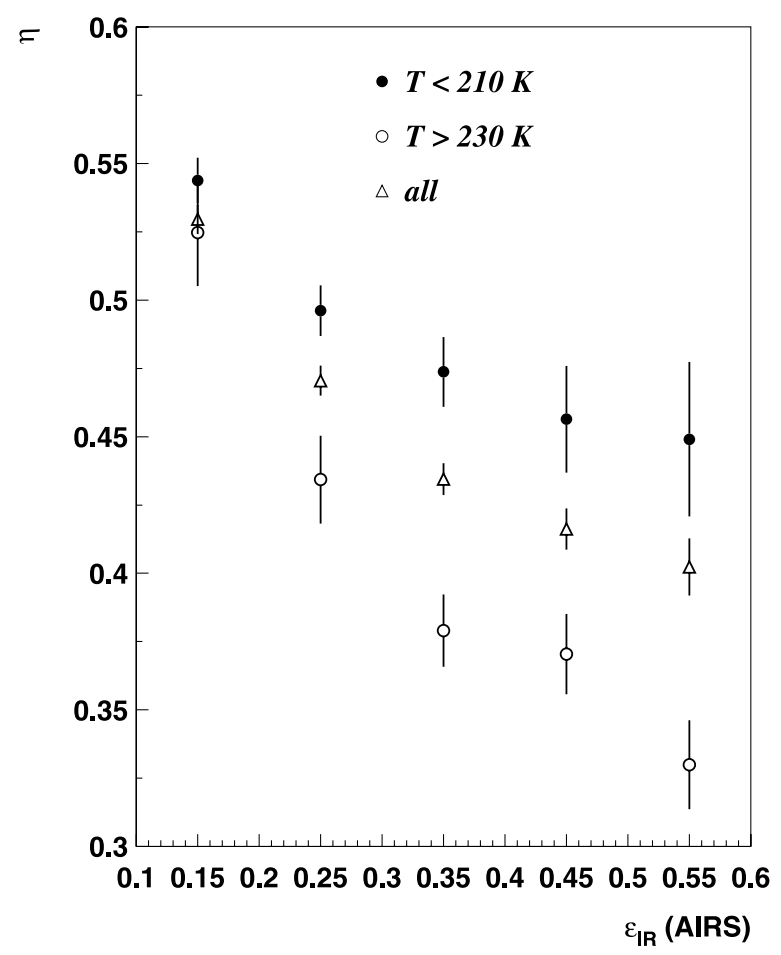

Figure 2. Multiple scattering coefficient $\eta$ as a function of AIRS infrared emissivity $\epsilon_{I R}: T<210 \mathrm{~K}, T>230 \mathrm{~K}$, and $T<$ $240 \mathrm{~K}$ (all cases). Tropics, $30^{\circ} \mathrm{N}-30^{\circ} \mathrm{S}, \alpha=2$. 


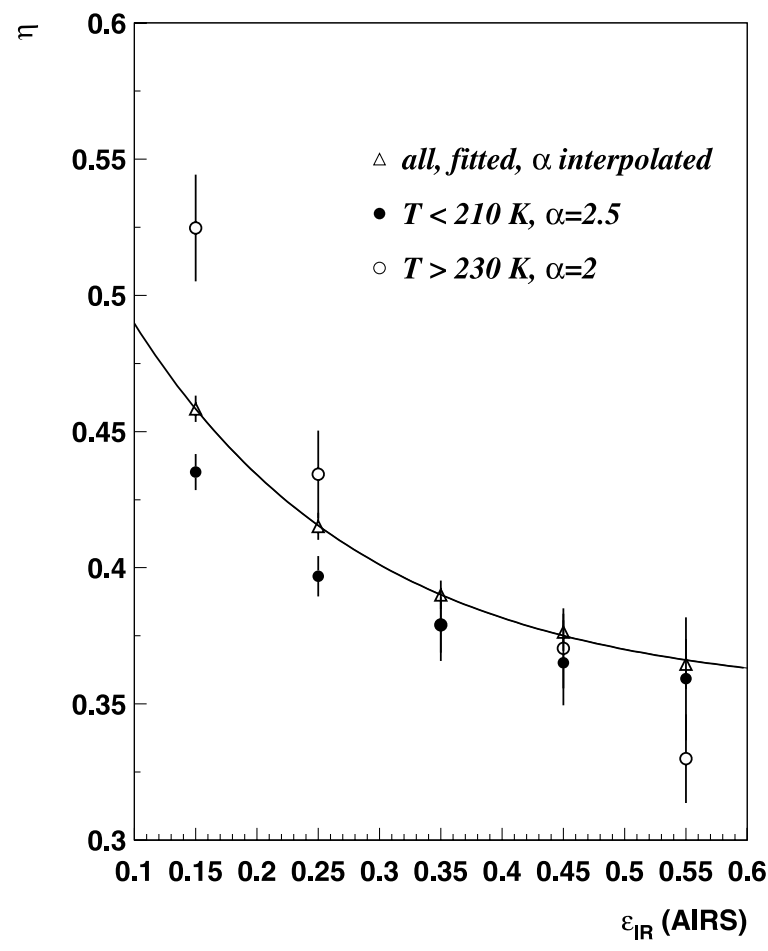

Figure 3. Multiple scattering coefficient $\eta$ as a function of AIRS infrared emissivity $\epsilon_{I R}: T<210 \mathrm{~K}$ with $\alpha=2.5, T>$ $230 \mathrm{~K}$ with $\alpha=2$, and for all temperatures $(T<240 \mathrm{~K})$ including previous cases and a linear interpolation $\alpha(T)$ between $T=210 \mathrm{~K}$ and $T=230 \mathrm{~K}$. Tropics, $30^{\circ} \mathrm{N}-30^{\circ} \mathrm{S}$.

Comstock and Sassen [2001] make the same suggestion and refer to Nicolas et al. [1997] who demonstrate single or double scattering are to be considered for optical depths $\tau<$ 1 and multiple scattering is to be considered for optical depths $\tau>1$. Comstock and Sassen [2001] use $\eta$ ranging between 0.9 and 0.6 , decreasing with thickening clouds.

[22] Because of the uncertainty of $\alpha$ in the computation of $\tau_{V I S}$ from $\epsilon_{I R}$, we will examine separately cold cirrus and warm cirrus. One would expect smaller ice crystal sizes in cold cirrus than in warm cirrus [e.g., Heymsfield and Platt, 1983; Donovan, 2003]. The latter should contain larger ice crystals for which $\alpha$ should be 2. Rädel et al. [2003] have shown by analyzing satellite data from the TIROS-N Operational Vertical Sounder (TOVS) that the mean effective ice crystal diameter for cirrus with $\epsilon_{I R} \in[0.3,0.85]$ is $55 \mu \mathrm{m}$. For smaller ice crystals $\alpha$ should be larger than 2, and in the following we estimate probable values for $\alpha$.

[23] Figure 2 presents average $\eta$ for five intervals of $\epsilon_{I R} \in$ $[0.1,0.6]$, for all cirrus clouds and separately for cold cirrus $\left(T_{\text {cld }}<210 \mathrm{~K}\right)$ and warm cirrus $\left(T_{\text {cld }}>230 \mathrm{~K}\right)$. For all cases $\alpha=2$ was used to convert $\epsilon_{I R}$ into $\tau_{V I S}$. As discussed in the beginning of section $3, \alpha=2$ is only justified for warm cirrus with $\epsilon_{I R}>0.3$. Here, it is interesting to note that $\eta$ is much larger for cold cirrus than for warm cirrus. This is because a constant extinction-to-absorption ratio $\alpha=2$ was applied. However, $\alpha=2$ is only justified for warm cirrus with $\epsilon_{I R}>0.3$. In the work by Sassen and Comstock [2001] this ratio is plotted as a function of the midcloud temperature for four cirrus categories over Salt Lake City, Utah. It varies between 2 and 3, with the highest values for the lowest temperatures. Increasing $\alpha$ leads to an increase of $\tau_{V I S}$ and then to a decrease of $\eta$. The discrepancy between cold and warm cirrus is therefore probably caused by an underestimation of $\alpha$ for cold clouds. In the work by Platt et al. [2002] theoretical values of $\alpha$ as a function of the effective diameter $D_{e}$ for different ice crystal types are shown, $\alpha>2.5$ is only inferred for values of $D_{e}<20 \mu \mathrm{m}$. Within the AIRS spatial resolution a collection of crystal sizes and shapes is observed at the same moment, resulting in average microphysical properties among which a mean $\alpha$ and a mean $D_{e}$, as with TOVS in the work by Rädel et al. [2003]. These considerations lead us to consider a maximum $\alpha=2.5$ as a good approximation for colder cirrus.

[24] In Figure 3 we plot $\eta$ derived for warm cirrus $\left(T_{\text {cld }}>\right.$ $230 \mathrm{~K})$ with $\alpha=2.0$ and for cold cirrus $\left(T_{c l d}<210 \mathrm{~K}\right)$ with $\alpha=2.5$. For $\epsilon_{I R}>0.3 \eta$ for cold cirrus is very close to $\eta$ for warm cirrus. Therefore, we define $\alpha$ as a linear function of $T_{\text {cld }}$ between these two extreme values of $\alpha=2.5$ at $T_{\text {cld }} \leq$ $210 \mathrm{~K}$ and $\alpha=2.0$ at $T_{\text {cld }} \geq 230 \mathrm{~K}$. We then show, also in Figure 3, $\eta$ for all cirrus using this function $\alpha\left(T_{c l d}\right) . \alpha\left(T_{c l d}\right)$ has an overall smoothing effect, and $\eta$ decreases slightly with $\epsilon_{I R}$. This indicates more MS and the need for a larger correction for higher optical depths, which agrees qualitatively with Comstock and Sassen [2001] and Chen et al. [2002]. Considering now the potential influence of the variation of $\alpha$, which we have just roughly estimated, we use the following uncertainties over the interpolated $\eta$ to be used: $\delta \eta=0.1$ for $\epsilon_{I R}<0.3$ and $\delta \eta=0.05$ for $\epsilon_{I R} \geq 0.3$.

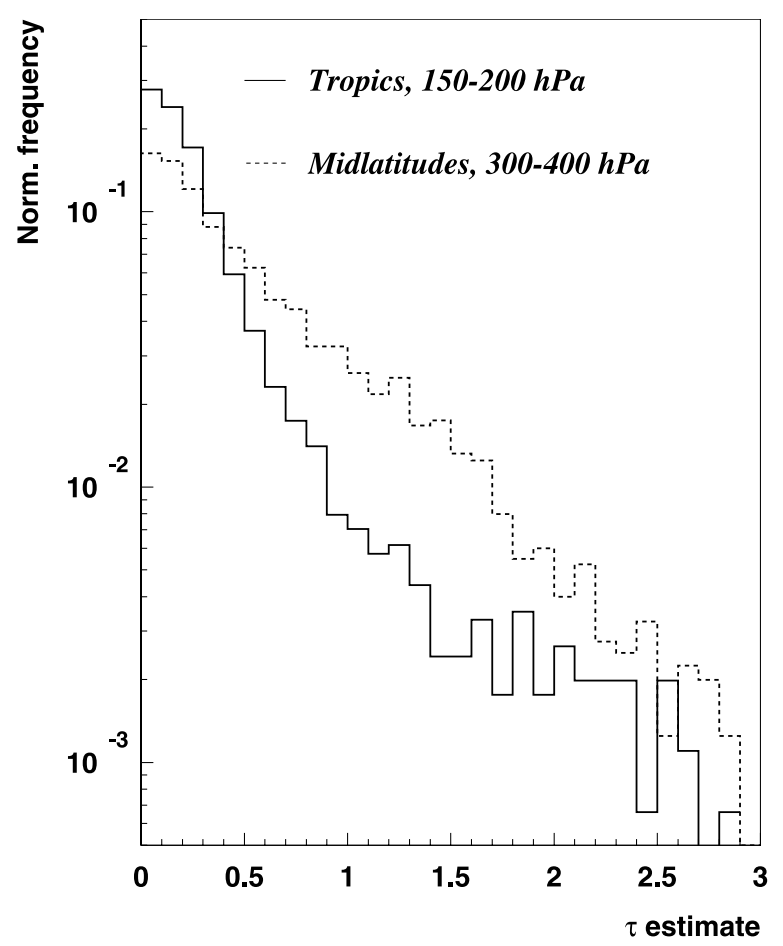

Figure 4. Normalized distributions (logarithmic scale) of optical depth $(\tau)$ estimates after correction with the function $\eta\left(\tau_{\text {LID }}\right)$. Tropics $\left(20^{\circ} \mathrm{N}-20^{\circ} \mathrm{S}\right)$ at $150-200 \mathrm{hPa}$ and midlatitudes $\left(40-60^{\circ} \mathrm{N}\right.$ and $\mathrm{S}$ combined) at $300-400 \mathrm{hPa}$. 


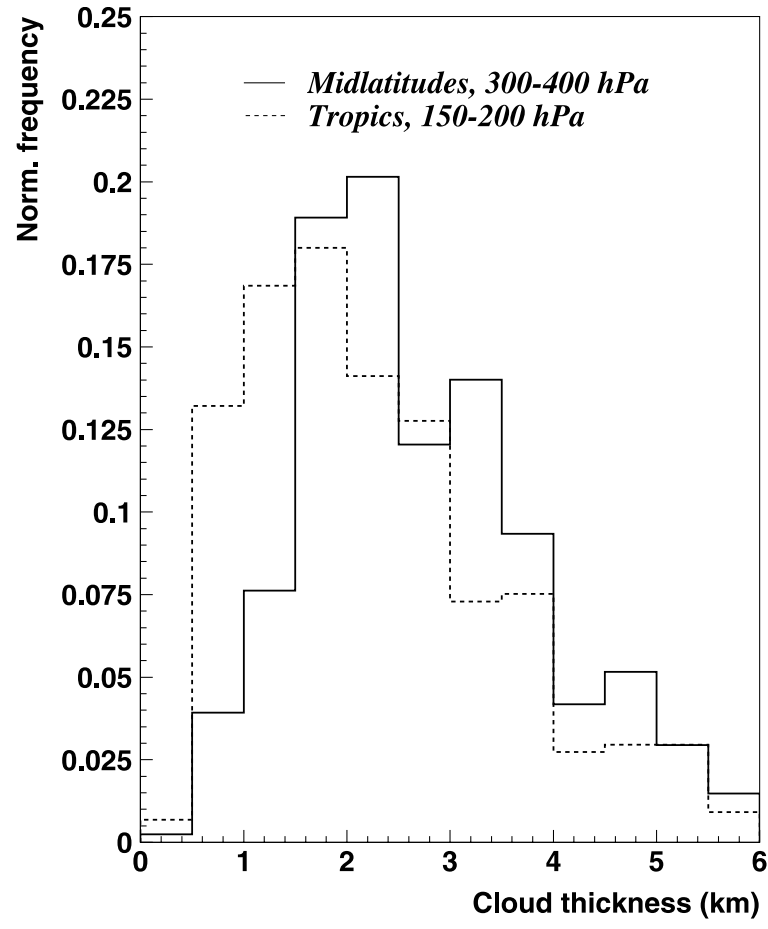

Figure 5. Normalized distributions of cloud geometrical thickness $(\mathrm{km})$, tropics $\left(20^{\circ} \mathrm{N}-20^{\circ} \mathrm{S}\right)$ at $150-200 \mathrm{hPa}$, midlatitudes $\left(40-60^{\circ} \mathrm{N}\right.$ and $\mathrm{S}$ combined) at $300-400 \mathrm{hPa}$.

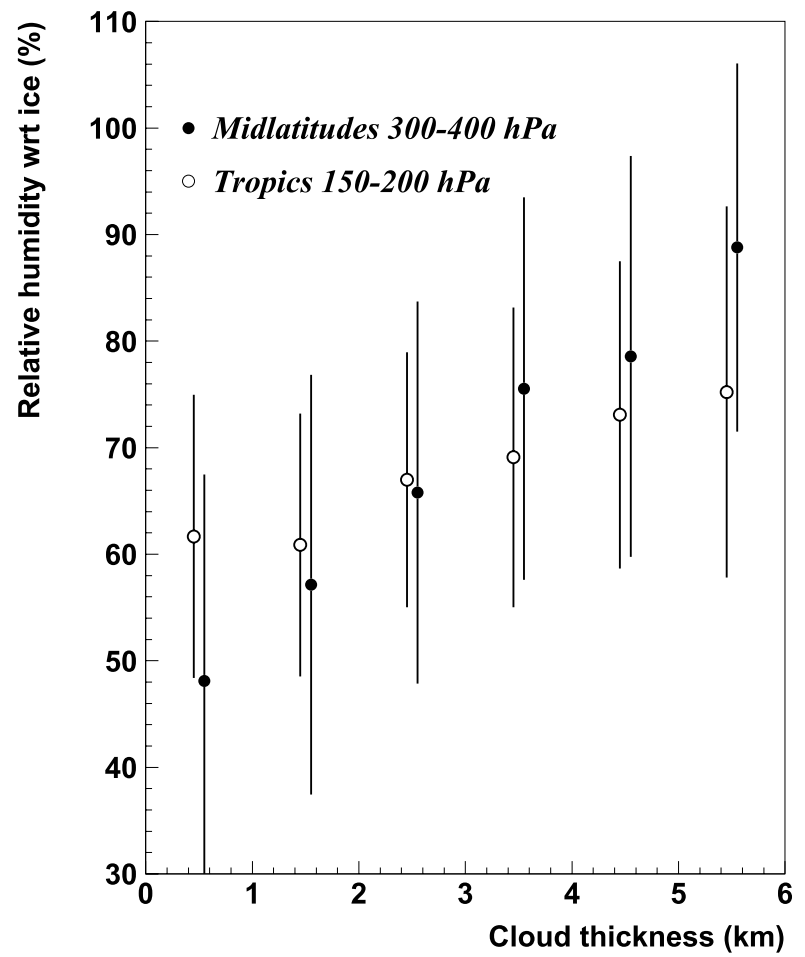

[25] We then approximate a relationship between $\eta$ and $\tau_{L I D}$ by using Figure 3 and the average $\tau_{L I D}$ computed for each interval of $\epsilon_{I R} . \eta$ is fitted as a function of $\tau_{L I D}$ as

$$
\eta\left(\tau_{L I D}\right)=0.36+0.19 \exp \left(0.31-5.97 \tau_{\text {LID }}\right)
$$

with the error bars defined above.

[26] We are now able to estimate optical depths from CALIPSO single-layer high clouds independently of the AIRS cloud properties which is only done for the tropical region. It must be kept in mind that this study aims only at roughly distinguishing cirrus optical depths. The advantage of using CALIPSO retrieved optical depth is to obtain coupled information on cloud geometrical thickness and cloud optical depth over the same CALIPSO pixel for discussing their relationships with RHice all the more because CALIPSO is able to detect subvisible cirrus as well as optically thicker cirrus.

\subsection{Distributions of CALIPSO Corrected Optical Depths for Cirrus}

[27] The function $\eta\left(\tau_{L I D}\right)$ is applied to correct "apparent" CALIPSO optical depth of single-layer cirrus clouds collocated with atmospheric profiles of good quality as described in 3.1. Figure 4 presents distributions of optical depth for single-layer clouds, with $p_{c l d}$ inside the layers $150-200 \mathrm{hPa}$ for the tropics and $300-400 \mathrm{hPa}$ for the midlatitudes, used in the analysis of the next section. In both latitudinal bands the distributions are peaked near zero, because the lidar also detects subvisible cirrus. The exponential decrease of the

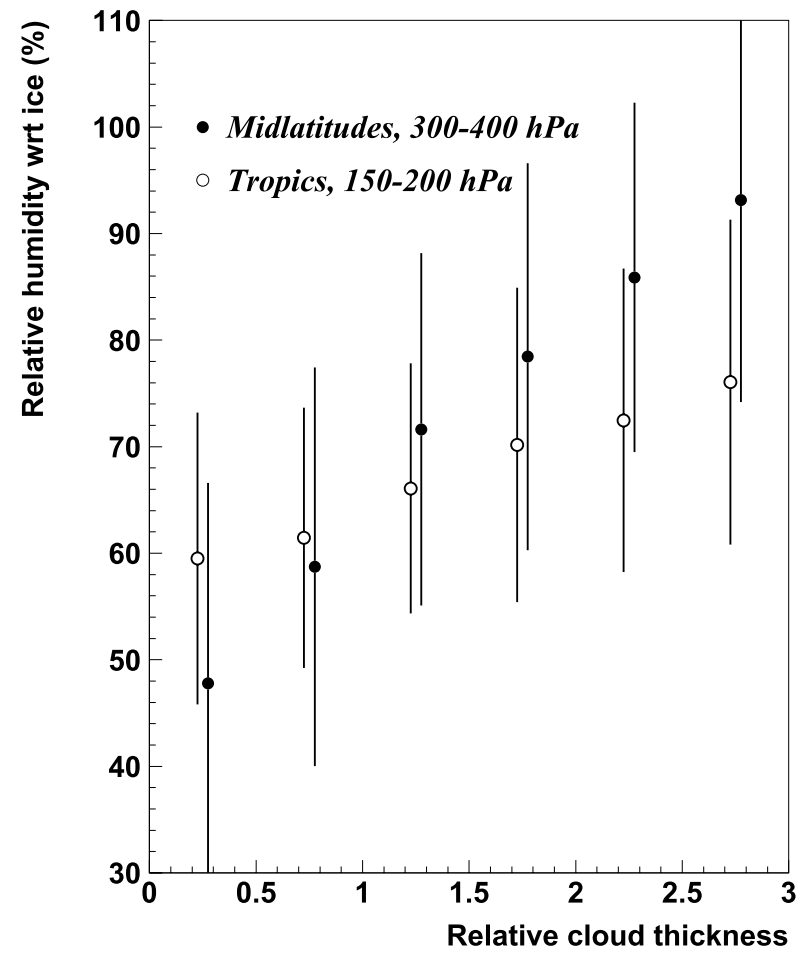

Figure 6. Relative humidity with respect to ice as a function of (left) cloud geometrical thickness (km) or (right) relative cloud thickness. Tropics $\left(20^{\circ} \mathrm{N}-20^{\circ} \mathrm{S}\right)$ at $150-200 \mathrm{hPa}$ and midlatitudes $\left(40-60^{\circ} \mathrm{N}\right.$ and $\mathrm{S}$ combined) at $300-400 \mathrm{hPa}$, error bars indicate standard deviation around mean value. 


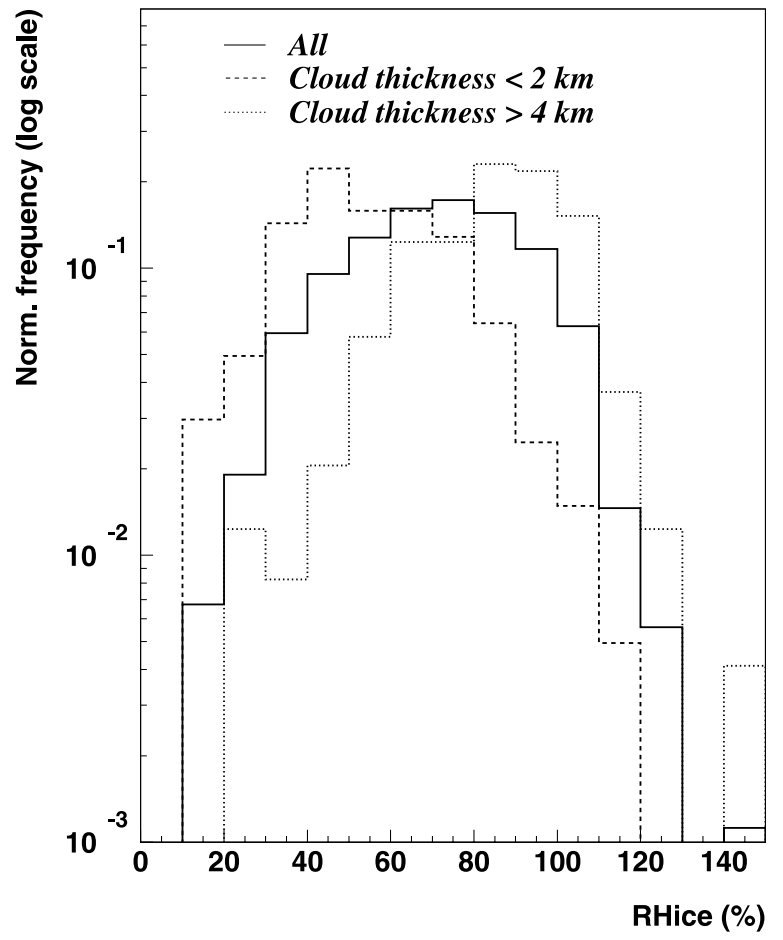

Figure 7. Normalized distributions of relative humidity with respect to ice. Midlatitudes $\left(40-60^{\circ} \mathrm{N}\right.$ and $\mathrm{S}$ combined) at 300-400 hPa: cloud geometrical thickness $<2 \mathrm{~km}$, cloud geometrical thickness $>4 \mathrm{~km}$, and all cases.

distributions appears in both latitudinal bands, with a narrower distribution for the tropics.

\section{Relationships Between RHice and Cirrus Properties}

[28] In this section we use the collocations within AIRS golf balls explained in 3.1, and we concentrate on high clouds in the layer $150-200 \mathrm{hPa}$ in the tropics and $300-400 \mathrm{hPa}$ in the midlatitudes as they are close to and below the tropopause and provide the highest number of events among the selected scenes (see again Figure 1).

\subsection{Correlation Between RHice and Cloud Thickness}

[29] Kahn et al. [2008], computing RHice as in the work by Gettelman et al. [2006] and not distinguishing different pressure layers, suggest that most probable values of RHice distributions around $60-80 \%$ may be caused by a geometrical thickness of cirrus clouds being smaller than the vertical resolution of temperature and specific humidity profiles (given $2-3 \mathrm{~km}$ ). However, we have observed that the thickness of the AIRS standard pressure layers in our analysis is quite similar to the vertical extent of cirrus found by CALIPSO (around $2 \mathrm{~km}$ ). The geometrical thickness of our selected layers corresponds to $1.8 \mathrm{~km}$ for the tropical layer $150-200 \mathrm{hPa}$ and to $1.9 \mathrm{~km}$ for the midlatitude layer $300-400 \mathrm{hPa}$. Cloud average thickness is found to be $\overline{\Delta z}=$ $1.9 \mathrm{~km}$ with standard deviation $\sigma_{\Delta z}=1.1 \mathrm{~km}$ for tropical cirrus in the layer $150-200 \mathrm{hPa}$ and $\overline{\Delta z}=2.1 \mathrm{~km}$ with standard deviation $\sigma_{\Delta z}=1.1 \mathrm{~km}$ for midlatitudinal cirrus in the layer 300-400 $\mathrm{hPa}$. A distribution of cloud thickness (CT) is shown in Figure 5, very large CT may seem unphysical but other authors have also observed some cirrus with large vertical extent both in the tropics and in the midlatitudes [e.g., Wang et al., 1997; Sassen and Comstock, 2001].

[30] We are now interested in how RHice is correlated with CT. To highlight the difference between the vertical extent of the cloud and the vertical extent of the pressure layer we also use relative cloud thickness (cloud thickness normalized by the thickness of the pressure layer). Figure 6 presents mean RHice for intervals of CT (Figure 6, left) and of relative cloud thickness (Figure 6, right) with standard deviations, indicating the width of each distribution. We assume the distribution in each interval to be nearly Gaussian. Each interval includes between 300 and 3000 points. We observe that mean RHice increases with cloud thickness in both latitudinal bands. The increase is much stronger in the midlatitudes than in the tropics $(50-90 \%$ versus $60-$ $75 \%$ ), probably linked to different formation mechanisms and consistent with Kahn et al. [2008, Figure 11]. CT in the work by Kahn et al. [2008] is limited to $4 \mathrm{~km}$. This is probably due to statistical reasons, which is supported by the distributions in Figure 5 showing a small amount of very large CT. We have tested the stability of the inferred relationship by considering separately land and ocean scenes and by considering only the CALIPSO pixel in the middle of the AIRS golf ball. Results are similar, showing the robustness of this relationship. A mean RHice close to $100 \%$ is only approached in the midlatitudes for clouds much more vertically extended than the standard pressure layer. However, when the cirrus vertical extent is the same as the vertical extent of the pressure layer (relative cloud thickness around 1) mean RHice is only about $65 \%$.

[31] One reason for the low values of mean RHice is the variation of the humidity within the pressure layers and how drier or moister parts of the profile are taken into account by the retrieval over a larger vertical extent. Small-scale fluctuations but also vertical gradients of humidity [e.g., Sakai et al., 2003] may lead to an underestimation of RHice. One has to consider the variability of RHice between the cloud and its environment as well as the variability of RHice inside the cloud [e.g., Comstock et al., 2004]. Especially since the saturation pressure depends strongly on the temperature, the ratio of integrated values of humidity and saturation humidity will differ from the maximum of the ratios (maximum RHice) within the layer. The latter, helpful to determine the presence of ice supersaturation, is unfortunately not available and direct comparisons with collocated in situ measurements would be helpful for further investigations.

Figure 8. ( $\mathrm{a}$ and b) Relative humidity with respect to ice distributions, (c and d) cloud geometrical thickness (km) distributions, and (e and f) relative humidity with respect to ice as a function of cloud geometrical thickness for two distinct classes of optical depth $(\tau<0.5$ and $\tau>1.0)$. Figures $8 \mathrm{a}, 8 \mathrm{c}$, and $8 \mathrm{e}$ are for midlatitudes $\left(40-60^{\circ} \mathrm{N}\right.$ and $\mathrm{S}$ combined) $250-$ $300 \mathrm{hPa}$, and Figures 8b, 8d, and $8 \mathrm{f}$ are for midlatitudes $300-400 \mathrm{hPa}$. Error bars indicate standard deviation around mean values. 


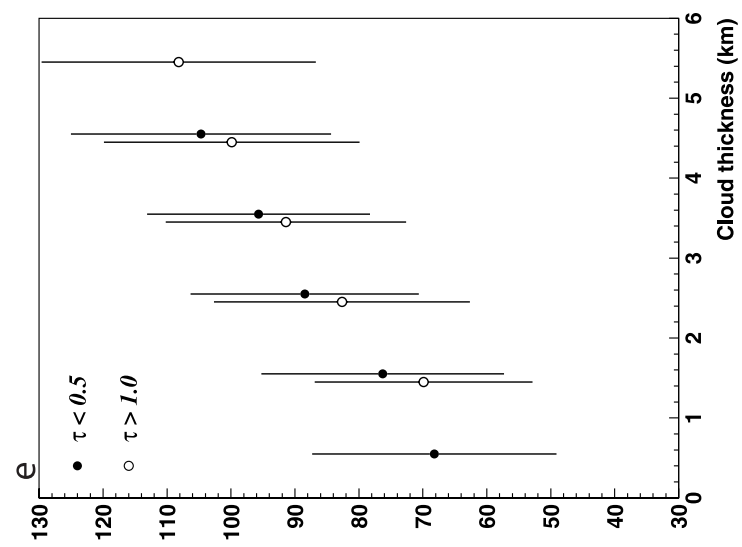

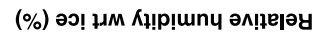
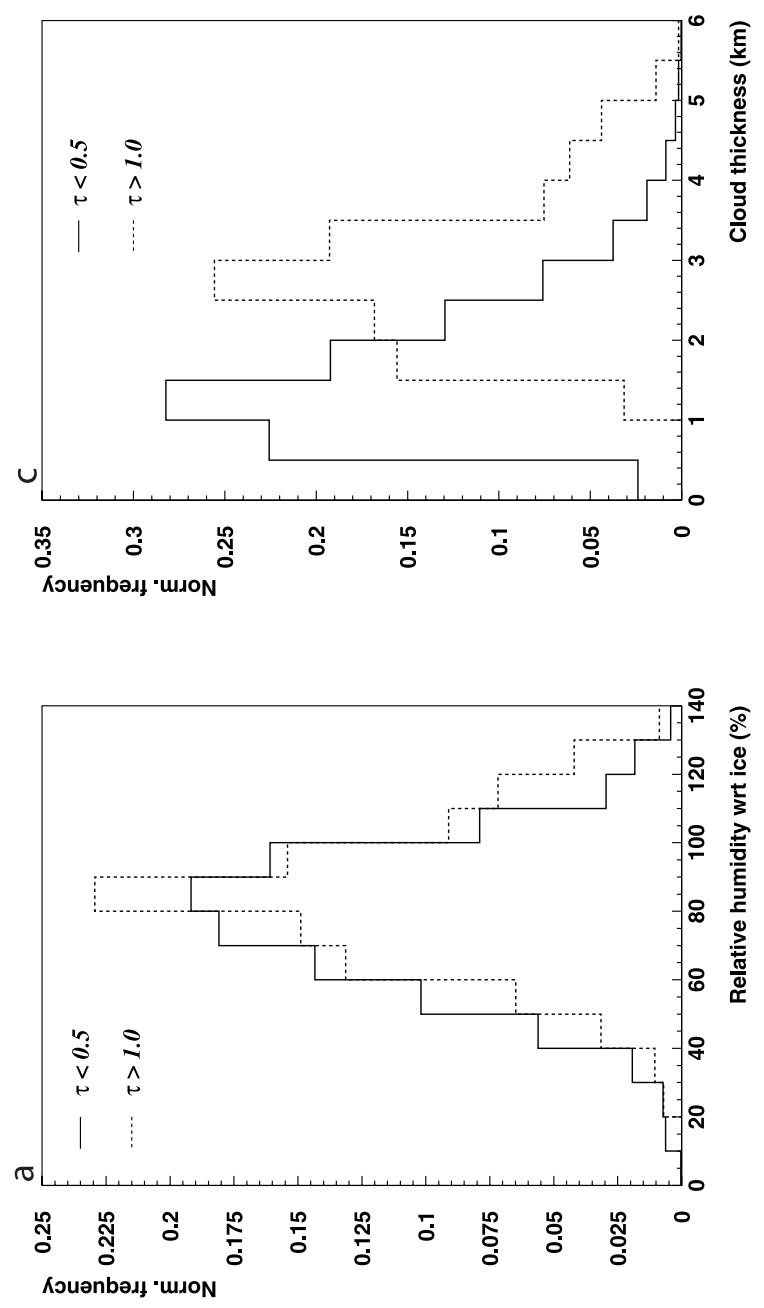

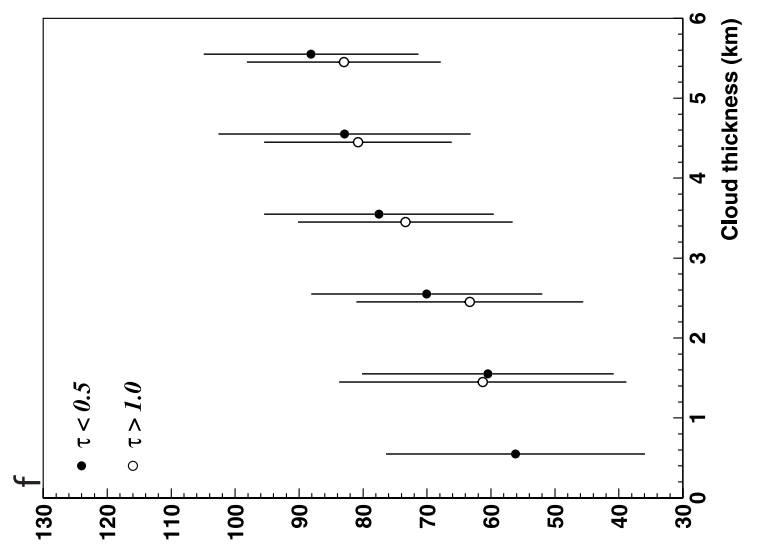

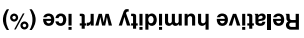
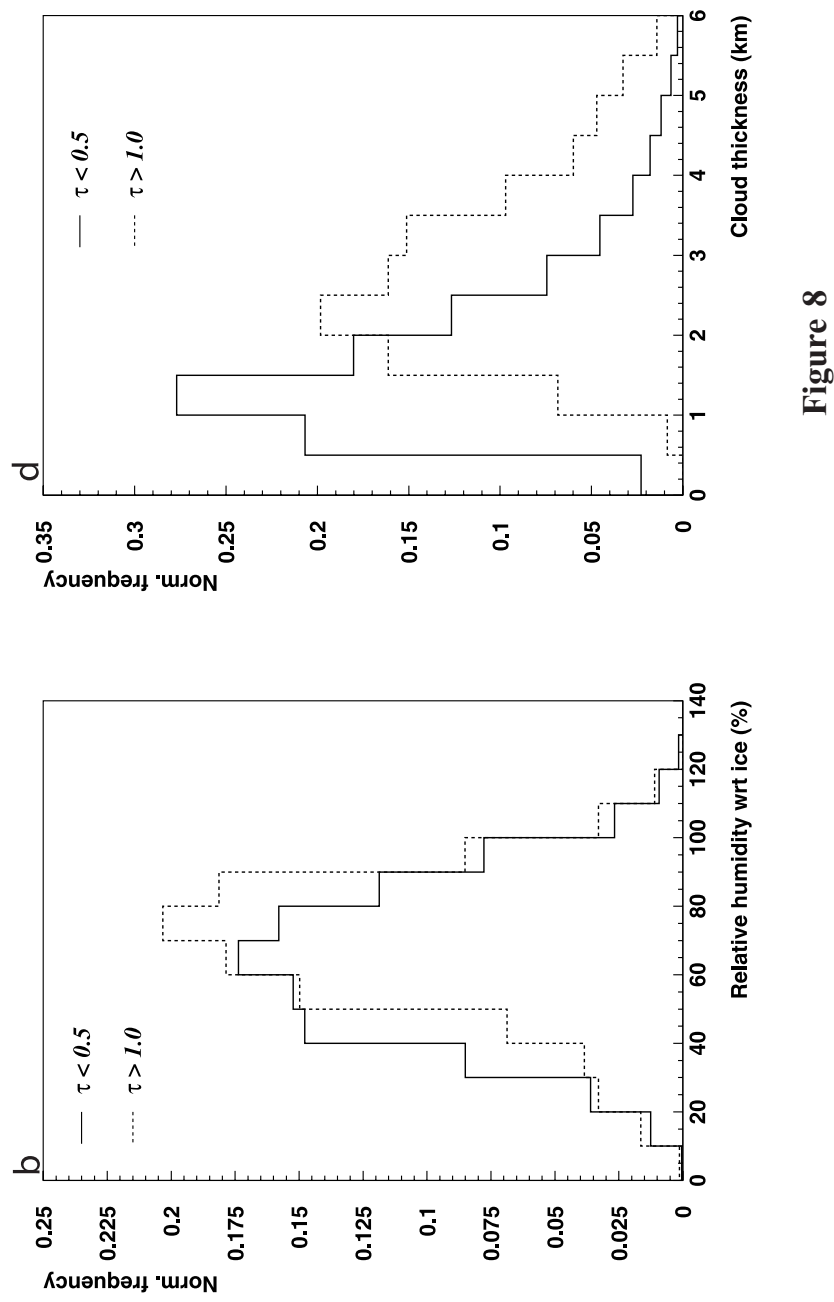
[32] Another reason arises from the distinction between the AIRS L2 vertical gridding and the actual vertical resolution. Even though many authors [Gettelman et al., 2004; Susskind et al., 2006; Tobin et al., 2006] argue a vertical resolution of temperature and moisture products of $2-3 \mathrm{~km}$ (more or less the size of the standard gridding) a recent study [Maddy and Barnet, 2008] shows that the vertical resolution of temperature and humidity profiles from AIRS could be much coarser, especially in situations with small vertical temperature gradients in the upper troposphere. The temperature (resp. specific humidity) resolutions are found to be $6-7 \mathrm{~km}$ (resp. $\approx 4 \mathrm{~km}$ ) over a corresponding $100-300 \mathrm{hPa}$ pressure layer and $\approx 4 \mathrm{~km}$ (resp. $\approx 3 \mathrm{~km}$ ) over a corresponding 300-600 hPa pressure layer. Mean RHice close to $100 \%$ is only approached in the midlatitudes for clouds extending vertically to $5-6 \mathrm{~km}$, which is then more in line with the figures given by Maddy and Barnet [2008] at 300-600 hPa.

[33] These points raise concerns on the ability of AIRS to detect ice supersaturation as dry biases may also occur over clear sky profiles with thin portions of supersaturated air inside, all the more as supersaturation is suspected to occur on even thinner portions of the profile than clouds (for a case in the midlatitudes see Spichtinger et al. [2003]).

[34] Figure 7 shows RHice distributions obtained for the midlatitudes in the layer $300-400 \mathrm{hPa}$ : we distinguish between geometrically thin $(C T<2 \mathrm{~km})$ and geometrically thick $(C T>4 \mathrm{~km})$ clouds, both compared to the overall distribution. The peaks of the distributions are located at $40-50 \%$ for $C T<2 \mathrm{~km}$ and located at $90-100 \%$ for $C T>$ $4 \mathrm{~km}$ while the peak of the overall distribution is situated at $70-80 \%$. The overall RHice distributions can be seen as the sum of the distributions of each interval of CT weighted by the probability of the given CT. As indicated by the standard deviations there exists a variability of RHice in each interval of CT representing various atmospheric conditions. For example, very thin cirrus clouds may be embedded in a large supersaturated region and then show a large RHice for a low CT, like persistent contrails with a large spatial cover [e.g., Duda et al., 2003].

[35] In the following section we examine a possible influence of the cloud optical depth on these relationships.

\subsection{Influence of Cloud Optical Depth}

[36] We use the corrected optical depths described in section 3. Considering the large uncertainties in our optical depth retrieval, two distinct classes of optical depths are defined: optically thin cirrus and optically thicker cirrus, with a gap to avoid overlapping between the categories. The optical depth distributions in Figure 4 (showing optically thicker cirrus in the midlatitudes) lead to use the following thresholds: $\tau<0.3(0.5)$ for thin cirrus and $\tau>0.6(1.0)$ for thicker cirrus in the tropics (midlatitudes). Error bars on $\tau$ result from uncertainties over $\eta(\tau)$ discussed in section 3, we show results using $\eta(\tau)$. Results are similar using $\eta(\tau) \pm$ $\delta \eta$ with $\delta \eta=0.05$ or $\delta \eta=0.1$ (not shown).
[37] For both cirrus classes we present distributions of RHice (Figures 8a, 8b, 9a, and 9b), distributions of cloud geometrical thickness (Figures 8c, 8d, 9c, and 9d) and mean RHice as function of cloud thickness (Figures $8 \mathrm{e}, 8 \mathrm{f}, 9 \mathrm{e}$, and 9f). These are shown in Figure 8 for the midlatitudes in 250-300 hPa (Figures 8a, 8c, and 8e) and 300-400 hPa layers (Figures 8b, 8d, and 8f), and in Figure 9 for the tropics in 150-200 hPa (Figures 9a, 9c, and 9e) and 200$250 \mathrm{hPa}$ layers (Figures 9b, 9d, and 9f).

[38] Regarding the distributions of relative humidity, on average a larger cloud optical depth infers a slightly larger mean RHice and a much larger cloud geometrical thickness for both latitudinal bands and for both layers. A large variability of geometrical thickness exists in each category of optical depths. In the tropics, this is consistent with studies of Wang et al. [1997] with the Stratospheric Aerosol and Gas Experiment (SAGE II): they find a wide range of geometrical thicknesses among subvisible cirrus $(\tau<0.02)$ including both very thin and very thick clouds (up to $6 \mathrm{~km}$ ). In the midlatitudes it is consistent with Sassen and Comstock [2001] who find a large standard deviation when correlating cirrus optical depth and cloud geometrical thickness.

[39] In the work by Kahn et al. [2008] RHice distributions are obtained for five classes of thin cirrus between $\tau=$ 0 and $\tau=1$ using 29 days of retrieved AIRS cloud properties. The distributions also peak around lowest values for optically thinnest clouds. These distributions were obtained regardless of the vertical extent of the clouds, and a direct effect of this is the large width of the distributions. We use the classification of $\tau$ described above to investigate how the relationship between RHice and the vertical extent of the clouds found in Figure 6 is affected.

[40] Figures 8 and 9 also present RHice as a function of cloud thickness for the two classes of optical depth. The same intervals as in Figure 6 are used, and the error bars indicate again the standard deviation of the distributions in each interval. Intervals containing less than 100 points are not taken into account. We observe that, for a comparable geometrical thickness, RHice is in general slightly larger for the smallest optical depths than for the largest optical depths with a difference up to $5 \%$ in both latitudinal bands and for all layers. This makes sense as it might be more probable that the former class contains more cirrus in formation whereas the latter contains more clouds well after formation, which may have depleted a larger part of water vapor, leading to a decrease of the observed mean relative humidity. These results also show that the geometrical thickness of clouds has a greater influence on the mean RHice than the optical depth, which corroborates [Kahn et al., 2008] on this matter.

[41] A last point of concern remains the global differences of mean RHice between the two pressure layers in each region. On one hand the midlatitudes $250-300 \mathrm{hPa}$ curves show an average of $15 \%$ more relative humidity compared to the $300-400 \mathrm{hPa}$ curves, which may be a consequence of an averaging of humidity over higher hence colder portions

Figure 9. (a and b) Relative humidity with respect to ice distributions, (c and d) cloud geometrical thickness (km) distributions, and (e and f) relative humidity with respect to ice as a function of cloud geometrical thickness for two distinct classes of optical depth $(\tau<0.3$ and $\tau>0.6)$. Figures 9a, 9c, and 9e are for the tropics $\left(20^{\circ} \mathrm{N}-20^{\circ} \mathrm{S}\right) 150-200 \mathrm{hPa}$, and Figures $9 \mathrm{~b}, 9 \mathrm{~d}$, and $9 \mathrm{f}$ are for the tropics $200-250 \mathrm{hPa}$. Error bars indicate standard deviation around mean values. 


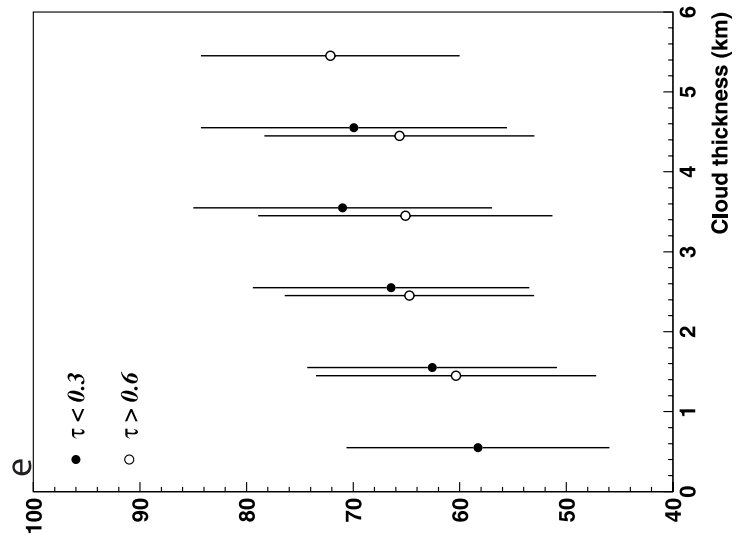

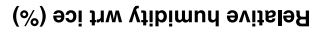
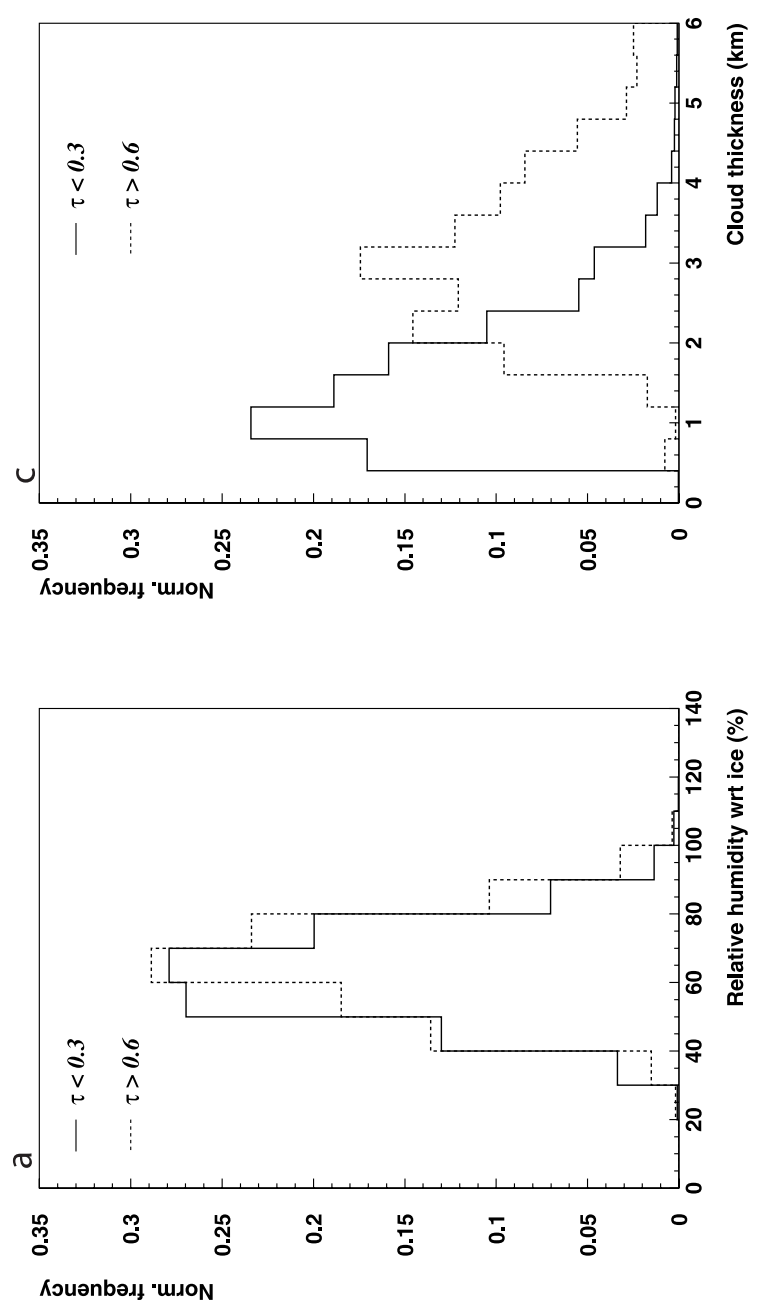

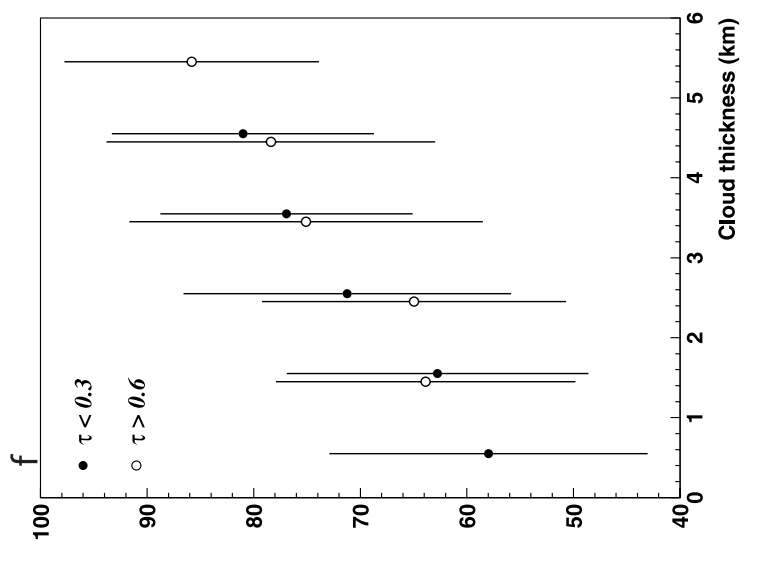

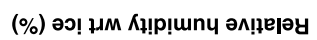
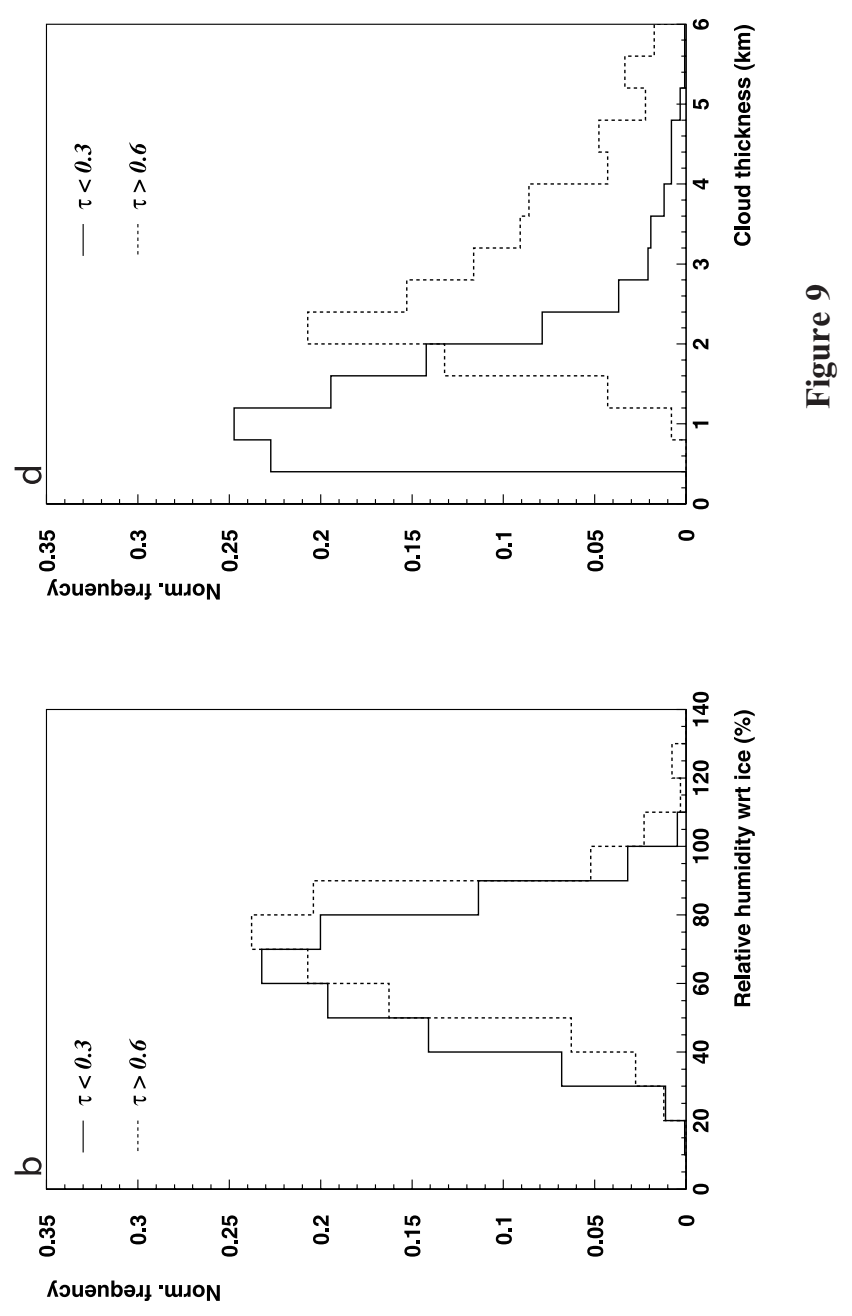
of the atmosphere [e.g., Korolev and Isaac, 2006] or an artefact due to a smaller pressure layer. Also, because of the selection with regard to the tropopause, the layer 250$300 \mathrm{hPa}$ considers a larger proportion of summer scenes.

[42] On another hand the tropics show a reverse tendency with $5 \%$ to $15 \%$ more RHice for large cloud thicknesses in the $200-250 \mathrm{hPa}$ layer which contradicts the previous observation. Although RHice values are good enough in the $150-200 \mathrm{hPa}$ to show the influence of cloud geometrical thickness and optical depth on the mean RHice they may not fit the same quality as the $200-250 \mathrm{hPa}$ layer (differences in RHice distributions for the two classes of optical depth are less well resolved for the layer $150-$ $200 \mathrm{hPa}$ ). This is consistent with [Gettelman et al., 2004] who show with airborne validations of AIRS that RHice quality is questionable at pressures lower than $200 \mathrm{hPa}$. Moreover, the RHice values found in the layer $200-$ $250 \mathrm{hPa}$ are more in line with those given by Kahn et al. [2008].

[43] More statistics and complementary information on particle size distribution, ice water content or dynamical situations can help clarify further the relationships found in Figures 8 and 9 and are the subjects of ongoing research.

\section{Conclusions}

[44] We have shown that the synergy of the instruments of the "A-Train" provides a more detailed insight on relationships between atmospheric conditions and cloud properties.

[45] The collocation of AIRS and CALIPSO cloud properties allowed us to estimate the multiple scattering contribution on "apparent" optical depths retrieved for single-layer high clouds. Plausible values of the extinction-to-absorption ratio were found to increase with a decrease of cloud temperature. The multiple scattering contribution shows a slight increase with cloud optical depth. We investigated the influence of cirrus geometrical thickness on RHice over pressure layers separately for the tropics $\left(20^{\circ} \mathrm{N}-20^{\circ} \mathrm{S}\right)$ and for the midlatitudes $\left(40-60^{\circ} \mathrm{N}\right.$ and $\mathrm{S}$ combined). In both latitude bands RHice increases with cirrus geometrical thickness but RHice remains low compared to $100 \%$ except for very vertically extended clouds. The influence of cloud optical depth on this relationship has then been examined. At fixed geometrical thickness, mean RHice is slightly higher for lowest optical depths (up to 5\%), suggesting more depletion of water vapor among optically thickest clouds. This study shows that the geometrical thickness of clouds has a greater influence than the optical depth on the mean RHice determined over standard pressure layers from AIRS, moister peaks in RHice distributions of optically thick cirrus being a consequence of a higher probability for larger geometrical thickness.

[46] At coarse vertical resolution an average RHice as low as $50 \%$ can indicate the presence of ice supersaturation [e.g., Gierens et al., 2004]. Integrating humidity over large vertical layers affects the detection of ice supersaturation (RHice $>100 \%$ ), a direct consequence being that frequencies of ice supersaturation are underestimated [Gettelman et al., 2006]. Therefore, a threshold lower than $100 \%$ may be applied [Stubenrauch and Schumann, 2005; Rädel and Shine, 2008] to detect supersaturation occurring inside large pressure layers. However, the great variability of humidity vertical and horizontal gradients as well as different biases while considering clear or cloudy skies may imply a certain amount of false alarms, which is not yet quantified and may depend on the portion of the upper troposphere over which RHice is determined.

[47] Acknowledgments. The AIRS version 5 data were obtained through the Goddard Earth Sciences Data and Information Services (http://daac.gsfc.nasa.gov/), and the CALIPSO data were obtained through the Atmospheric Sciences Data Center (ASDC) at NASA Langley Research Center by the ICARE Thematic Center created by CNES (http://wwwicare.univ-lille1.fr/) and its interface ClimServ created for Institut Pierre Simon de Laplace (http://climserv.ipsl.polytechnique.fr/). The authors thank all the corresponding teams for assistance and public release of data products. This work was performed at Laboratoire de Météorologie Dynamique at Ecole Polytechnique, France, and the authors thank the Atmospheric Radiation Analysis team. The authors thank Stéphane Marchand for technical support with the CALIPSO code and David Winker for fruitful discussions. And, last but not least, the authors thank three anonymous reviewers for their concerned, useful, and complementary comments.

\section{References}

Chédin, A., N. A. Scott, C. Wahiche, and P. Moulinier (1985), The improved initialization inversion method: A high resolution physical method for temperature retrievals from satellites of the TIROS-N series, J. Clim. Appl. Meteorol., 24, 128-143.

Chen, W.-N., C.-W. Chiang, and J.-B. Nee (2002), Lidar ratio and depolarization ratio for cirrus clouds, Appl. Opt., 41, 6470-6476.

Chepfer, H., J. Pelon, G. Brogniez, C. Flamant, V. Trouillet, and P. H. Flamant (1999), Impact of cirrus cloud ice crystal shape and size on multiple scattering effects: Application to spaceborne and airborne backscatter lidar measurements during LITE mission and E-LITE campaign, Geophys. Res. Lett., 26, 2203-2206.

Chevallier, F., F. Cheruy, N. A. Scott, and A. Chédin (1998), A neural network approach for a fast and accurate computation of longwave radiative budget, J. Appl. Meteorol., 37, 1385-1397.

Comstock, J. M., and K. Sassen (2001), Retrieval of cirrus cloud radiative and backscattering properties using combined lidar and infrared radiometer (LIRAD) measurements, J. Atmos. Oceanic Technol., 18, 1658-1673.

Comstock, J. M., T. P. Ackerman, and D. D. Turner (2004), Evidence of high ice supersaturation in cirrus clouds using ARM Raman lidar measurements, Geophys. Res. Lett., 31, L11106, doi:10.1029/ 2004GL019705

Donovan, D. P. (2003), Ice-cloud effective particle size parameterization based on combined lidar, radar reflectivity, and mean Doppler velocity measurements, J. Geophys. Res., 108(D18), 4573, doi:10.1029/ 2003JD003469.

Duda, D. P., P. Minnis, L. Nguyen, and R. Palikonda (2003), A case study of the development of contrail clusters over the Great Lakes, J. Atmos. Sci., 61, 1132-1146.

Gettelman, A., et al. (2004), Validation of Aqua satellite data in the upper troposphere and lower stratosphere with in situ aircraft instruments, Geophys. Res. Lett., 31, L22107, doi:10.1029/2004GL020730.

Gettelman, A., E. J. Fetzer, A. Eldering, and F. W. Irion (2006), The global distribution of supersaturation in the upper troposphere from the Atmospheric Infrared Sounder, J. Clim., 19, 6089-6103.

Gierens, K., and P. Spichtinger (2000), On the size distribution of ice supersaturation regions in the upper troposphere and lower stratosphere, Ann. Geophys., 17, 1218-1226.

Gierens, K., R. Kohlhepp, P. Spichtinger, and M. Schroedter-Homscheidt (2004), Ice supersaturation as seen from TOVS, Atmos. Chem. Phys., 4, $539-547$.

Haag, W., B. Kärcher, J. Ström, A. Minikin, U. Lohmann, J. Ovarlez, and A. Stohl (2003), Freezing thresholds and cirrus cloud formation mechanisms inferred from in situ measurements of relative humidity, Atmos. Chem. Phys., 3, 1-33.

Heymsfield, A. J., and C. M. R. Platt (1983), A parameterization of particle size spectrum of ice clouds in terms of the ambient temperature and the ice water content, J. Atmos. Sci., 41, 846-855.

Immler, F., R. Treffeisen, D. Engelbart, K. Krüger, and O. Schrems (2007), Cirrus, contrails, and ice supersaturated regions in high pressure systems at northern midlatitudes, Atmos. Chem. Phys., 7, 13,175-13,201.

Kahn, B. H., C. K. Liang, A. Eldering, A. Gettelman, Q. Yue, and K. N. Liou (2008), Tropical thin cirrus and relative humidity observed by the Atmospheric Infrared Sounder, Atmos. Chem. Phys., 8, 1501-1518. 
Kley, D., H. G. J. Smit, S. Nawrath, Z. Luo, P. Nedelec, and R. H. Johnson (2007), Tropical Atlantic convection as revealed by ozone and relative humidity measurements, J. Geophys. Res., 112, D23109, doi:10.1029/ 2007JD008599.

Korolev, A., and G. A. Isaac (2006), Relative humidity in liquid, mixedphase, and ice clouds, J. Atmos. Sci., 63, 2865-2880.

Lohmann, U., B. Kärcher, and J. Hendricks (2004), Sensitivity studies of cirrus clouds formed by heterogeneous freezing in the ECHAM GCM, J. Geophys. Res., 109, D16204, doi:10.1029/2003JD004443.

Luo, Z., D. Kley, R. H. Johnson, and H. G. J. Smit (2007), Ten years of measurements of tropical upper-tropospheric water vapor by MOZAIC, part I: Climatology, variability, transport and relation to deep convection, J. Clim., 20, 418-435.

Maddy, E. S., and C. D. Barnet (2008), Vertical resolution estimates in Version 5 of AIRS operational retrievals, IEEE Trans. Geosci. Remote Sens., 46, 2375-2384.

McGill, M. J., M. A. Vaughan, C. R. Trepte, W. D. Hart, D. L. Hlavka, D. M. Winker, and R. Kuehn (2007), Airborne validation of spatial properties measured by the CALIPSO lidar, J. Geophys. Res., 112, D20201, doi:10.1029/2007JD008768.

Minnis, P., K. N. Liou, and Y. Takano (1993), Inference of cirrus clouds properties using satellite-observed visible and infrared radiances. Part I: Parameterization of radiance fields, J. Atmos. Sci., 50, 1279-1304.

Nicolas, F., L. R. Bissonnette, and P. H. Flamant (1997), Lidar effective multiple-scattering coefficients in cirrus clouds, Appl. Opt., 36, 34583468 .

Ovarlez, J., J.-F. Gayet, K. Gierens, J. Ström, H. Ovarlez, F. Auriol, R. Busen, and U. Schumann (2002), Water vapour measurements inside cirrus clouds in Northern and Southern hemispheres during INCA, Geophys. Res. Lett., 29(16), 1813, doi:10.1029/2001GL014440.

Platt, C. M. R. (1973), Lidar and radiometric observations of cirrus clouds, J. Atmos. Sci., 30, 1191-1204.

Platt, C. M. R., S. A. Young, R. T. Austin, G. R. Patterson, D. L. Mitchell, and S. D. Miller (2002), LIRAD observations of tropical cirrus clouds in MCTEX. Part I: Optical properties and detection of small particles in cold cirrus, J. Atmos. Sci., 59, 3145-3162.

Pruppacher, H. R. (1994), A new look at homogeneous ice nucleation in supercooled water drops, J. Atmos. Sci., 52, 1924-1933.

Rädel, G., and K. P. Shine (2008), Radiative forcing by persistent contrails and its dependence on cruise altitudes, J. Geophys. Res., 113, D07105, doi:10.1029/2007JD009117.

Rädel, G., C. J. Stubenrauch, R. Holz, and D. L. Mitchell (2003), Retrieval of effective ice crystal size in the infrared: Sensitivity study and global measurements from TIROS-N Operational Vertical Sounder, J. Geophys. Res., 108(D9), 4281, doi:10.1029/2002JD002801.

Read, W., J. Waters, D. Flower, L. Froidevaux, R. Jarnot, D. Hartmann, R. Harwood, and R. Rood (1995), Upper-tropospheric water vapor from UARS MLS, Bull. Am. Meteorol. Soc., 76, 2381-2389.

Read, W. G., et al. (2007), Aura Microwave Limb Sounder upper tropospheric and lower stratospheric $\mathrm{H}_{2} \mathrm{O}$ and relative humidity with respect to ice validation, J. Geophys. Res., 112, D24S35, doi:10.1029/ 2007JD008752.

Sakai, T., T. Nagai, M. Nakazato, Y. Mano, and T. Matsumura (2003), Ice clouds and Asian dust studied with lidar measurements of particle extinction-to-backscatter ratio, particle depolarization, and water-vapor mixing ratio over Tsukuba, Appl. Opt., 42, 7103-7116.

Sassen, K. (1991), The polarization lidar technique for cloud research: A review and current assessment, Bull. Am. Meteorol. Soc., 72, 1848-1866.

Sassen, K., and J. M. Comstock (2001), A midlatitude cirrus cloud climatology from the facility for atmospheric remote sensing. Part III: Radiative properties, J. Atmos. Sci., 58, 2113-2127.
Sonntag, D. (1990), Important new values of the physical constants of 1986, vapor pressure formulation based on the ITS-90 and psychrometer formulae, Z. Meteorol., 70, 340-344.

Spichtinger, P., K. Gierens, U. Leiterer, and H. Dier (2003), Ice supersaturation in the tropopause region over Lindenberg, Germany, Meteorol. Z., $12,143-156$.

Spichtinger, P., K. Gierens, H. G. J. Smit, J. Ovarlez, and J.-F. Gayet (2004), On the distribution of relative humidity in cirrus clouds, Atmos. Chem. Phys., 4, 639-647.

Stephens, G., et al. (2002), The CloudSat mission and the A-train, Bull. Am. Meteorol. Soc., 83, 1771-1790.

Stubenrauch, C. J., and U. Schumann (2005), Impact of air traffic on cirrus coverage, Geophys. Res. Lett., 32, L14813, doi:10.1029/2005GL022707.

Stubenrauch, C. J., A. Chédin, R. Armante, and N. A. Scott (1999), Clouds as seen by infrared sounders (3I) and imagers (ISCCP). Part II: A new approach for cloud parameter determination in the 3I algorithms, J. Clim., $12,2214-2223$.

Stubenrauch, C. J., F. Eddounia, and L. Sauvage (2005), Cloud heights from TOVS Path-B: Evaluation using LITE observations and distributions of highest cloud layers, J. Geophys. Res., 110, D19203, doi:10.1029/2004JD005447.

Stubenrauch, C. J., S. Cros, N. Lamquin, R. Armante, A. Chédin, C. Crevoisier, and N. A. Scott (2008), Cloud properties from Atmospheric Infrared Sounder and evaluation with Cloud-Aerosol Lidar and Infrared Pathfinder Satellite Observations, J. Geophys. Res., doi:10.1029/ 2008JD009928, in press.

Susskind, J., C. Barnet, and J. Blaisdell (2003), Retrieval of atmospheric and surface parameters from AIRS/AMSU/HSB data in the presence of clouds, IEEE Trans. Geosci. Remote Sens., 41, 390-409.

Susskind, J., C. Barnet, J. Blaisdell, L. Iredell, F. Keita, L. Kouvaris, G. Molnar, and M. Chahine (2006), Accuracy of geophysical parameters derived from AIRS/AMSU as a function of fractional cloud cover, J. Geophys. Res., 111, D09S17, doi:10.1029/2005JD006272.

Tobin, D. C., H. E. Revercomb, R. O. Knuteson, B. M. Lesht, L. L. Strow, S. E. Hannon, W. F. Feltz, L. A. Moy, E. J. Fetzer, and T. S. Cress (2006), Atmospheric Radiation Measurement site atmospheric state best estimates for Atmospheric Infrared Sounder temperature and water vapor retrieval validation, J. Geophys. Res., 111, D09S14, doi:10.1029/ 2005JD006103.

Wang, P.-H., P. Minnis, M. P. McCormick, G. S. Kent, G. K. Yue, D. F. Young, and K. M. Skeens (1997), A study of the vertical structure of tropical $\left(20^{\circ} \mathrm{S}-20^{\circ} \mathrm{N}\right)$ optically thin clouds from SAGE II observations, Atmos. Res., 47-48, 599-614.

Winker, D. M. (2003), Accounting for multiple scattering in retrievals from space lidar, Proc. SPIE Int. Soc. Opt. Eng., 5059, 128-139.

Winker, D. M., R. H. Couch, and M. P. McCormick (1996), An overview of LITE: NASA's Lidar In-space Technology Experiment, Proc. IEEE, 84 $164-180$.

Winker, D. M., J. Pelon, and M. P. McCormick (2003), The CALIPSO mission: Spaceborne lidar for observation of aerosols and clouds, Proc. SPIE Int. Soc. Opt. Eng., 4893, 1-11.

Winker, D. M., W. H. Hunt, and M. J. McGill (2007), Initial performance assessment of CALIOP, Geophys. Res. Lett., 34, L19803, doi:10.1029/ 2007 GL030135.

Wylie, D. P., E. Eloranta, J. D. Spinhirne, and S. P. Palm (2007), A comparison of cloud cover statistics from the GLAS lidar with HIRS, J. Clim., $20,4968-4981$.

N. Lamquin and C. J. Stubenrauch, Laboratoire de Météorologie Dynamique, Ecole Polytechnique, IPSL, CNRS, F-91128 Palaiseau, France. (nicolas.lamquin@lmd.polytechnique.fr)

J. Pelon, Service d'Aéronomie, IPSL, Université Pierre et Marie Curie, CNRS, F-75252 Paris, France. 